\title{
Evaluating the Applicability of a Social Content Management Framework: A Case Analysis
}

\author{
Wan Azlin Zurita Wan Ahmad ${ }^{1,}$ Muriati Mukhta ${ }^{2}$ \\ Faculty of Information Science and Technology \\ Universiti Kebangsaan Malaysia \\ Bangi, Malaysia
}

\author{
Yazrina Yahya ${ }^{3}$ \\ Faculty of Economy and Management \\ Universiti Kebangsaan Malaysia \\ Bangi, Malaysia
}

\begin{abstract}
Social media platform plays an important role in engaging customers. The social content resulting from social media interactions between the organisations and the customers need a proper management. Therefore, in this work, a framework for social content management is introduced to support the management of social content. This framework is developed based on two main concepts. The first is the existing concepts that are present in content management, whilst the second concept is derived from the theory of service science. This approach is adopted to cater for existing concepts in enterprise content management, that are relevant to social content management and also to cater for the concept of value cocreation which forms the basis of engagement between the organisations and the customers. The applicability of the proposed social content management framework needs to be evaluated in order to determine the extent of its applicability in practical situations. Therefore, the main focus of this article is to report the usability of the proposed framework against the practices of the government agencies of Malaysia in managing the social content. The evaluation method used is based on the score of system usability scale. The results from the evaluation revealed that the proposed framework is usable and is deemed practical to be used in organisations.
\end{abstract}

Keywords-Service science; social content; social content management; social media; value co-creation

\section{INTRODUCTION}

Social media as a new platform, is fast becoming an important tool in assisting organisations to formulate strategies and engagement initiatives between the organisations and their customers. Social media has also become a channel for the source of information for engagement [1], [2]. A study by [3] proves that social media is able to produce open innovation in policies and services offered by organisations, by taking into account the direct needs of the customers. Besides that, a research by [4] stated that the digital infrastructure such as a social media platform would foster digital innovation in the organisations. Social media interactions also could impact on the risk perception [5]. Based on this significance, content from the interactions between the organisations and the customers on social media platforms needs to be taken care of. Therefore, social content management is introduced to manage the social content resulting from social media interactions.

Social media facilitates value co-creation between the organisations and its customers which benefit both parties.
Thus, value co-creation is an aspect that needs to be emphasized in the management of social content. Value cocreation is one of the main concepts in service science [6]-[9]. Hence, the social content management framework is formed based on a service science perspective (see Fig. 1). From the service science perspective, this framework (see Fig. 1) adopted the theory of service dominant logic (SD-L) and the DART model. With the application of SD-L, it highlighted the actors, identification of service, the application of resource, and the exchange of service [6]. It also give attention to institutions and institutional arrangement to govern the process and perform on holistic ecosystem [6]. Apart from that, the DART model, which emphasises on the components of engagement platform, experience domain and also a capable ecosystem heading towards co-creation of value and outcomes of all actors involve [10]-[12]. The DART model has similarity with the process in content lifecycle which is the factor under the service exchange [13].

Detailed explanations of the framework in Fig. 1 is stated in earlier research by [13] and [14]. Briefly, Fig. 1 shows the relationships between the elements and factors that formed a social content management based on science service perspective. A social content management is the dynamic process of collecting social content, resulting from active participation between organisations and customers on social media platforms. These interactions are supported by resource integrations and service exchanges. This dynamic process should be controlled by related institutions and institutional arrangement that occur within a good service ecosystem. The actors involved in social content management could be divided into two groups, namely, the organisations and the customers. For the purpose of managing content, three levels of organisational management are involved, namely, top management level, tactical level management (namely, middle management), and operational level management. These three levels have different roles in managing social content. The top management level plays the role of determining the policies and direction of social content management. The tactical level management is involved in managing social content and conducting analytical analysis. The operational level management is directly involved in the interaction process with the customers to collect and manage the social contents at the early stage. Social content is important for enabling service innovations because the customers' needs are obtained directly during the process of capturing contents through the active interactions between the organisations and the 
customers. Hence, social content should be managed to ensure that the organisations could produce accurate results based on input from social interactions, which could lead to innovations in the services offered.

Such framework needs to be evaluated to test it applicability in a real working environment. Therefore, this article is focusing on the evaluation of the framework. Four organisations from the government of Malaysia are chosen as case studies in this research to show the practicality of the proposed framework. The system usability scale (SUS) score is used to show the level of usability of the developed framework in the selected government agencies of Malaysia.

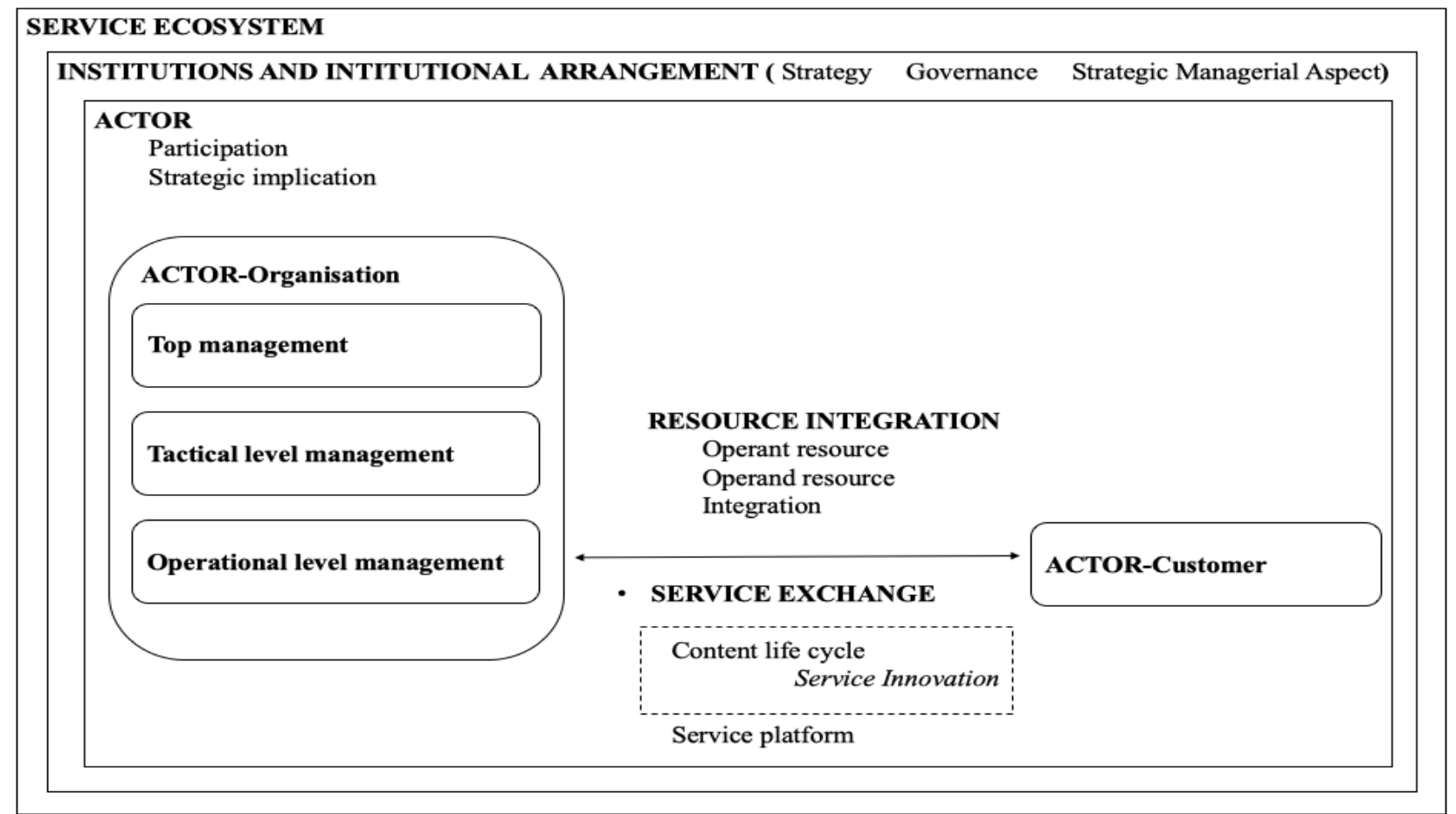

Legend

CAPITAL WORD illustrate the element Sentence word illustrate the factor

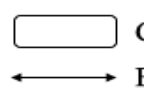
Category of actor Engagement of actor
Service innovation is produce during the process of content lifecycle

Fig. 1. Social Content Management Framework based on Service Science Perspective [13].

\section{MAterial AND Method}

In this study, a case study is used to evaluate the framework. One of the questions asked in the case study protocol is "Based on the explanation on the framework and the understanding of the guideline, is the proposed framework useable for the organisation?". Therefore, the SUS score is adopted in this study to evaluate the usability of the framework. For this article, the research method that is adopted is illustrated in Fig. 2.

Further explaination of the research method is in the next sub-section

\section{A. Protocol Development}

In this study, there are three main activities in protocol development as follows:

1) Guideline development based on the framework:-A high-level guideline is developed based on the proposed framework in order to explain the framework in detail. The guideline guides the organisations to manage the social content based on the elements and factors that have been identified. Besides that, the guideline means to ensure the organisations are aware of how the framework works in assisting the organisations to manage the social content. Write-up of the guideline consist of the four chapters namely,

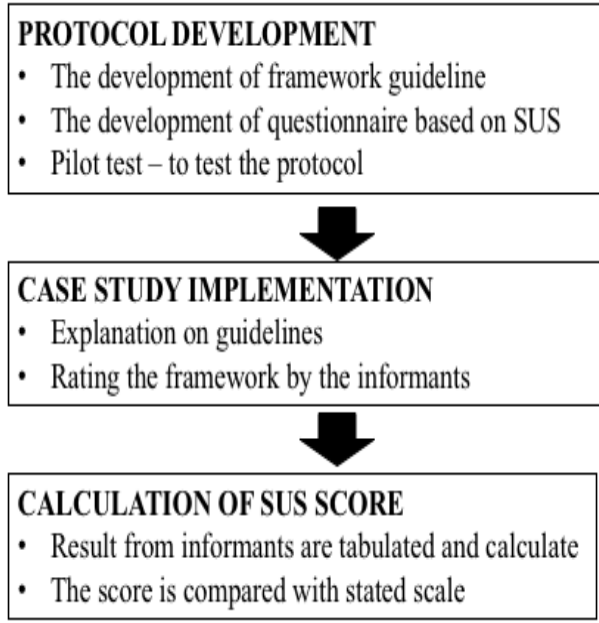

Fig. 2. Research Method. 
- First chapter is "Introduction". This chapter explains on what is social content, social content management, the importance of managing social content. This chapter also explains on how to use the guideline.

- Second chapter is "Social content management framework based on service science perspective". This chapter briefly explain on the framework as well as elements and factors that contribute to the development of the framework.
- Third chapter is "Guideline for organisation." This chapter describe the high-level guideline on how the organisation should manage the social content. The explanation is given on all elements and factors that affect the management of social content as stated in second chapter. In addition, the checklist also provided in the guidelines according to the factors. Summary of checklist for the guideline is in Table I.

- Fourth chapter is "Conclusion" that conclude the guideline.

TABLE I. SUMMARY OF CHECKLIST FOR GUIDELINE

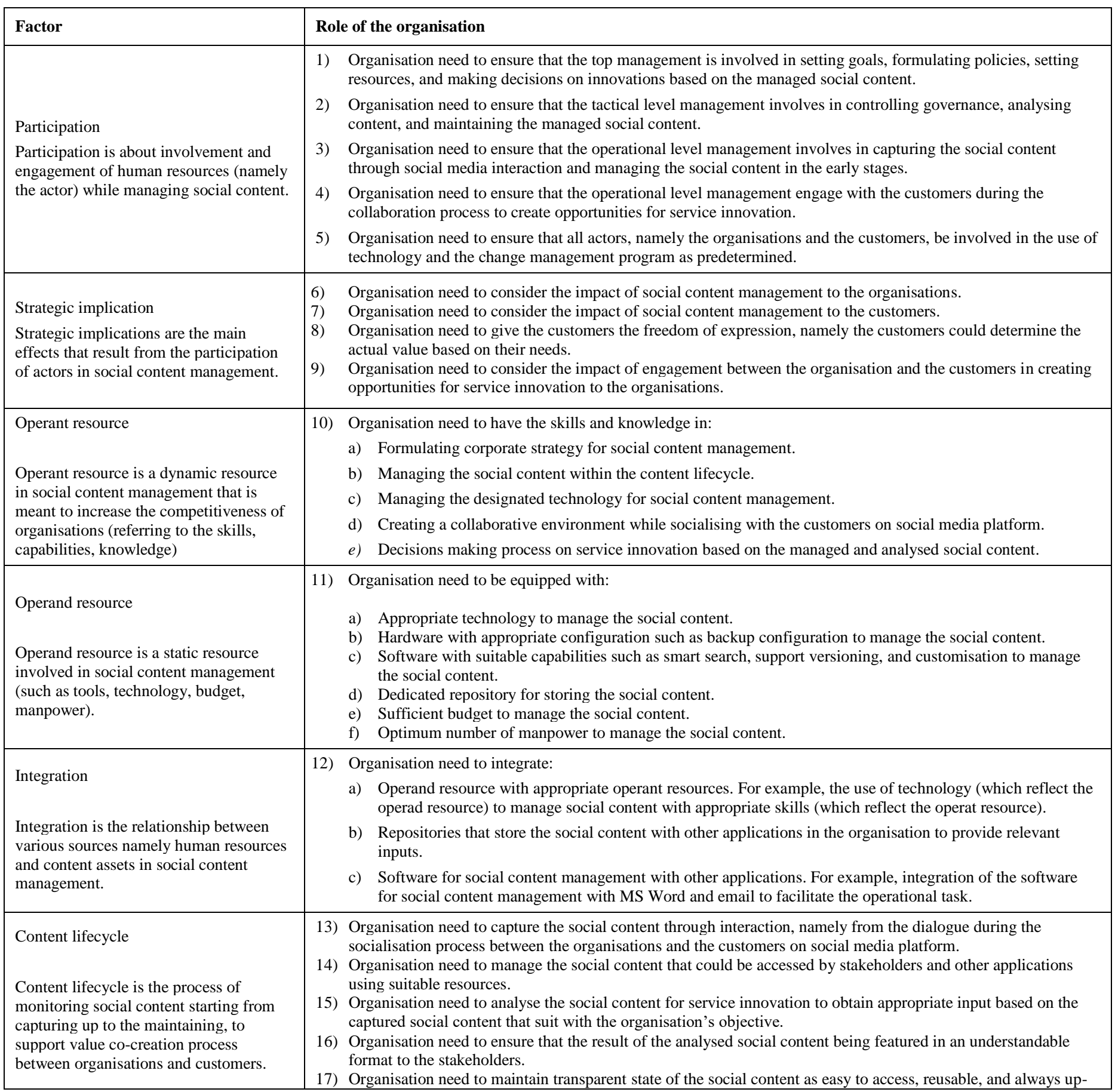




\begin{tabular}{|c|c|c|}
\hline & & to-date. \\
\hline $\begin{array}{l}\text { Service platform } \\
\text { Service platform is the space of } \\
\text { interaction in managing social content to } \\
\text { increase the efficiency of service } \\
\text { exchange (such as systems). }\end{array}$ & 18) & $\begin{array}{l}\text { Organisation need to ensure the service platform is: } \\
\text { a) Flexible. } \\
\text { b) Has a user-friendly interface. } \\
\text { c) Facilitates relationships between different content categories. For example, to improve the organisation } \\
\text { policy with the input from the customers, there is a need to provide the content from different categories that } \\
\text { are tied together, namely from the category of interaction (ie. comment section on social media platform) } \\
\text { and the policy documents. }\end{array}$ \\
\hline $\begin{array}{l}\text { Strategy } \\
\text { Strategy is the planning, measures and } \\
\text { methods in the management of social } \\
\text { content to meet the needs of the } \\
\text { organisations and the customers. }\end{array}$ & $\begin{array}{l}\text { 19) } \\
\\
\\
\text { 20) } \\
\text { 21) } \\
\text { 22) }\end{array}$ & $\begin{array}{l}\text { Organisation need to ensure that social content management strategies are designed with the aspects of, } \\
\text { a) Actor-driven. } \\
\text { b) Content-driven. } \\
\text { c) Process-driven. } \\
\text { d) Technology-driven } \\
\text { e) The mechanism for managing the social content. } \\
\text { f) The planning for change management program. } \\
\text { Organisation need to ensure that the management of social content is at the optimum level. } \\
\text { Organisation need to ensure that the social content is captured and analysed conforming to the organisational } \\
\text { objectives. } \\
\text { Organisation need to ensure that challenges in managing social content are reduced to highlighting value in the } \\
\text { designated strategy. }\end{array}$ \\
\hline $\begin{array}{l}\text { Governance } \\
\text { Governance is an administrative routine } \\
\text { for controlling the social content } \\
\text { management in order to ensure the } \\
\text { integrity of the content, which involves } \\
\text { various human resources and content } \\
\text { assets. }\end{array}$ & $\begin{array}{l}\text { 23) } \\
\text { 24) } \\
\text { 25) }\end{array}$ & $\begin{array}{l}\text { Organisation need to comply with existing policies based on organisational objectives. For example, the } \\
\text { management of social content need to comply with the Organisation's ICT Security Policy to ensure the security } \\
\text { aspect of managing the social content. } \\
\text { Organisation need to create new policies that are appropriate for managing social content. For example, the } \\
\text { administrative instructions to facilitate the process of managing the social content. } \\
\text { Organisation need to have a sound governance structure such as committees or specific unit in the organisation } \\
\text { to oversee the management of social content. } \\
\text { Organisation need to set a clear role to all actors involved in managing the social content. }\end{array}$ \\
\hline $\begin{array}{l}\text { Strategic managerial aspect is the } \\
\text { acceptance of the actors to changes in } \\
\text { technology, administration and content } \\
\text { management methods and the increase in } \\
\text { the level of competence of actors. }\end{array}$ & $\begin{array}{l}\text { 27) } \\
28)\end{array}$ & $\begin{array}{l}\text { Organisation need to get the commitment of all actors involved. } \\
\text { Organisation need to have a robust change management program namely, } \\
\text { a) Appropriate training programs for all actors involved such as analytical and soft skills training. } \\
\text { b) Awareness programs at every level of management in the organisation. } \\
\text { c) Awareness and engagement programs with the customers. }\end{array}$ \\
\hline $\begin{array}{l}\text { Service ecosystem } \\
\text { Service ecosystem is a holistic } \\
\text { environment that allows the value co- } \\
\text { creation process to take place in the } \\
\text { social content management. }\end{array}$ & $\begin{array}{l}\text { 29) } \\
\text { 30) } \\
\text { 31) } \\
\text { 32) } \\
\text { 33) } \\
\text { 34) }\end{array}$ & $\begin{array}{l}\text { Organisation need to ensure that social content management considers the organisational workflows. } \\
\text { Organisation need to consider a good project management mechanism to facilitate the development of } \\
\text { innovative services based on the analysed social content. } \\
\text { Organisation need to consider the need for risk mitigation. } \\
\text { Organisation need to consider the management of social content perform in a good and conducive environment. } \\
\text { Organisation need to emphasise on active collaboration between various actors towards providing service } \\
\text { innovation. } \\
\text { Organisation need to promote knowledge sharing based on the managed social content. }\end{array}$ \\
\hline
\end{tabular}

2) Questionnaire development based on system usability scale:- SUS is a scale that was introduced by [15]. It could be applied to measure the usability of the system in an organisation [15]-[17]. The SUS provides a simple and easy administrative questionnaire as well as produce reliable results with a small sample size of informants [15]. Furthermore, in a previous study, [18] adapted the SUS score in order to assess the usability of the framework in the organisation. Based on [18], the original questionnaire is amended, namely by changing of term "system" to the "framework". Hence, this study applied the SUS score to evaluate the usability of the proposed framework. The template of questionnaire is based on SUS as stated in Table II. The SUS questionnaire consists of subjective evaluation with ten items measured. It is based on a Likert scale of five, namely from "1-strongly disagree" to "5-strongly agree".

3) Pilot test:- The objective of the pilot test is to review the suitability and accuracy of the developed protocol. A pilot test was conducted at Agency X, a central agency in the government of Malaysia that plans and manages ICT implementation. This agency also manages and implement the Project X, a project that provides convenient access to government services through a single point of contact. Project $\mathrm{X}$ captures citizen feedbacks and comments on all platforms including the social media. The protocol is improved based on comments from the informants in Agency X. 
TABLE II. TEMPLATE OF QUESTIONNAIRE [18]

\begin{tabular}{|c|c|c|c|c|c|}
\hline Please tick (/) in the column provided & 1 & 2 & 3 & 4 & \\
\hline $\begin{array}{l}\text { 1. I think I would like to use this framework } \\
\text { frequently }\end{array}$ & & & & & \\
\hline 2. I found the framework unnecessarily complex & & & & & \\
\hline 3. I thought the framework was easy to use & & & & & \\
\hline $\begin{array}{l}\text { 4. I think that I would need the support of a } \\
\text { technical person to be able to use the framework }\end{array}$ & & & & & \\
\hline $\begin{array}{l}\text { 5. I found various elements and factors in this } \\
\text { framework well integrated }\end{array}$ & & & & & \\
\hline $\begin{array}{l}\text { 6. I thought there was too much inconsistency in this } \\
\text { framework }\end{array}$ & & & & & \\
\hline $\begin{array}{l}\text { 7. I would imagine that most people would learn to } \\
\text { use this framework very quickly }\end{array}$ & & & & & \\
\hline 8. I found this framework very cumbersome to use & & & & & \\
\hline 9. I felt very confident using this framework & & & & & \\
\hline $\begin{array}{l}\text { 10. I needed to learn a lot of things before I could get } \\
\text { going with this framework }\end{array}$ & & & & & \\
\hline
\end{tabular}

\section{B. Implementation of Case Study}

According to [19], there are four types of case study, namely (1) single (holistic), (2) single (embedded), (3) multiple (holistic) and (4) multiple (embedded). As this study is not a unique study, hence multiple case study is more appropriate than single case study as it could give a diversity in data findings. Besides that, analytical units are important in case study design because they are fundamental to the study conducted [19]. This study emphasizes the management of the social content in the organisations by considering the needs of the customers, therefore, the appropriate unit of analysis is the "Organisation". Hence, this study applies to the third type of case study, namely the multiple (holistic) case study with the unit of analysis "Organisation".

A selection of case study is based on certain criteria. In the Malaysian environment, the government's focus is to enhance the service delivery by giving priority to the citizen by taking into consideration the views of the citizen in enhancing the quality of services offered by the government [20], [21]. Therefore, the organisations in the public sector begin to consider social content as input to service innovation. This is based on the Internet User Survey 2016 by [22], $69.6 \%$ of Internet users in Malaysia use social media to obtain information in the public sector compared to other communication channels. In addition, referring to [23], the most popular social media platform in Malaysia is Facebook with the percentage of $41 \%$.

Besides that, based on [19], the selection of case studies relies on two criteria, (1) access to data, and (2) access to more than one informant. In that regard, out of the ten agencies that got the highest "like" on Facebook, four public sector agencies of Malaysia were agreed to participate in the evaluation process using the SUS score. For the case study, the sessions were set with 11 informants from four different public sector agencies of Malaysia. The list of informants and their characteristics are listed in Table III.
TABLE III. INFORMANTS AND CHARACTERISTIC

\begin{tabular}{|c|c|c|}
\hline $\begin{array}{l}\text { Informant } \\
\text { ID }\end{array}$ & Characteristic of informant & Session \\
\hline \multicolumn{3}{|c|}{$\begin{array}{l}\text { Organisation A provides the education services to the citizen and safeguarding } \\
\text { the welfare of teachers }\end{array}$} \\
\hline A1 & $\begin{array}{l}\text { - The head of ICT Department. } \\
\text { - Top management level who involve in the } \\
\text { decision-making process include decision on } \\
\text { service innovation from the managed social } \\
\text { content. }\end{array}$ & 1 hour \\
\hline A2 & $\begin{array}{l}\text { - Manager in ICT Department. } \\
\text { - Tactical level of management in social content } \\
\text { management. } \\
\text { - Involves in the development of innovative } \\
\text { service initiatives, as a result from the analysed } \\
\text { social content. }\end{array}$ & 1 hour \\
\hline A3 & $\begin{array}{l}\text { - The head of social media unit who responsible in } \\
\text { managing official social media platform. } \\
\text { - Tactical and operational level of management. }\end{array}$ & 1 hour \\
\hline \multicolumn{3}{|c|}{ Organisation B leads the management and enforcement of road transport } \\
\hline B1 & $\begin{array}{l}\text { - Executive in the human resource department. } \\
\text { - Operational level of management in social } \\
\text { content management. }\end{array}$ & $\begin{array}{l}45 \\
\text { minutes }\end{array}$ \\
\hline B2 & $\begin{array}{l}\text { - The head of social media unit who responsible in } \\
\text { managing official social media platform. } \\
\text { - Tactical and operational level of management in } \\
\text { social content management. }\end{array}$ & 1 hour \\
\hline B3 & $\begin{array}{l}\text { - Senior manager of ICT department. } \\
\text { - Operational and tactical level of management in } \\
\text { social content management. }\end{array}$ & 1 hour \\
\hline
\end{tabular}

Organisation $\mathrm{C}$ responsible for the management and development of human resources in public services

\begin{tabular}{|c|c|c|}
\hline $\mathrm{C} 1$ & $\begin{array}{l}\text { - The head of social media unit who responsible in } \\
\text { managing official social media platform. } \\
\text { - Tactical and operational level of management in } \\
\text { social content management. }\end{array}$ & $\begin{array}{l}45 \\
\text { minutes }\end{array}$ \\
\hline $\mathrm{C} 2$ & $\begin{array}{l}\text { - Executive in social media unit. } \\
\text { - Operational level of management in social } \\
\text { content management. }\end{array}$ & $\begin{array}{l}45 \\
\text { minutes }\end{array}$ \\
\hline $\mathrm{C} 3$ & $\begin{array}{l}\text { - Executive in ICT department. } \\
\text { - Operational level of management in social } \\
\text { content management. } \\
\text { - Involves in the development of innovative } \\
\text { service initiatives, as a result of the analysed } \\
\text { social content. }\end{array}$ & 1 hour \\
\hline \multicolumn{3}{|c|}{ Organisation D responsible for fire and rescue } \\
\hline D1 & $\begin{array}{l}\text { - Manager in the human resource department. } \\
\text { - Operational level of management in social } \\
\text { content management. }\end{array}$ & $\begin{array}{l}45 \\
\text { minutes }\end{array}$ \\
\hline D2 & $\begin{array}{l}\text { - The head of social media unit who responsible } \\
\text { for managing official social media platform. } \\
\text { - Tactical and operational level of management in } \\
\text { social content management. }\end{array}$ & $\begin{array}{l}45 \\
\text { minutes }\end{array}$ \\
\hline
\end{tabular}




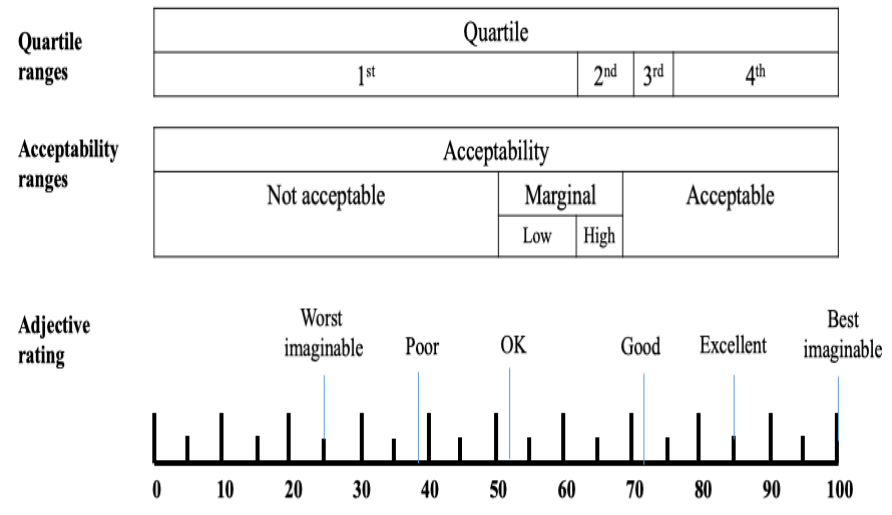

Fig. 3. SUS Score Value [15].

There were three main activities in the implementation of case study namely,

- individual informant was provided with the information on the framework and guidelines,

- individual informant was asked to evaluate the usability of the framework based on the SUS's questionnaire as stated in Table II, and

- the response was collected and analysed according to the predefined scale. The Bangor's SUS adjective scale based on quartiles as stated in Fig. 3 was referred as the scale in this study [15].

\section{Culculation of SUS Score}

For the purpose of calculating the SUS score, the steps set by [15] are as follows

- For odd numbered questions (Question number 1, 3, 5, $7,9)$, the score of each item is calculated individually as,

Odd score = individual value for odd question-" 1 "

- For even numbered questions (Question number 2, 4, 6, $8,10)$, the individual item score is calculated individually as,

Even score $=$ "5"- individual value for even question

- Formula to calculate the value of SUS (range between 0 to 100 ) is:

SUS score value $=$ Total score ("odd score" and "even score") * 2.5

- Mapping of SUS score values referring to the Bangor's SUS adjective scale (Refer Fig. 3).

\section{RESULT AND DISCUSSION}

The results of the analysis in the evaluation of the social content management framework, based on service science perspective, is given in Table IV. It is referring to the SUS score value rated by 11 informants from four different public sector agencies of Malaysia.
TABLE IV. RESUlt OF ANALYSIS BASED ON SUS SCORE VALUE

\begin{tabular}{|c|c|c|c|}
\hline Organisation & Informant ID & SUS Score & $\begin{array}{l}\text { Mean value of SUS } \\
\text { Score per } \\
\text { organisation }\end{array}$ \\
\hline \multirow{3}{*}{ Organisation A } & A1 & 90.00 & \multirow{3}{*}{87.50} \\
\hline & $\mathrm{A} 2$ & 87.50 & \\
\hline & A3 & 85.00 & \\
\hline \multirow{3}{*}{ Organisation B } & B1 & 85.00 & \multirow{3}{*}{86.67} \\
\hline & B2 & 87.50 & \\
\hline & B3 & 87.50 & \\
\hline \multirow{3}{*}{ Organisation $\mathrm{C}$} & $\mathrm{C} 1$ & 87.50 & \multirow{3}{*}{89.17} \\
\hline & $\mathrm{C} 2$ & 95.00 & \\
\hline & $\mathrm{C} 3$ & 85.00 & \\
\hline \multirow{2}{*}{ Organisation D } & D1 & 87.50 & \multirow{2}{*}{87.50} \\
\hline & D2 & 87.50 & \\
\hline \multicolumn{2}{|c|}{ Overall mean value of SUS score } & \multicolumn{2}{|l|}{87.73} \\
\hline
\end{tabular}

Referring to Fig. 3, the proposed framework is acceptable if the value of SUS score is obtained in the "third" and "fourth" quartiles as well as received the score of "70 and above". For individual organisation, all four different public sector agencies of Malaysia received the mean of SUS score value "above 85.0". Therefore, based on the Bangor's SUS adjective scale based on quartiles (Refer Fig. 3), the result for individual organisation shows,

- the quartile range for each public sector agency of Malaysia falls under the " $4^{\text {th }}$ quartile range",

- the acceptability ranges of the proposed framework for each public sector agency of Malaysia are at the "acceptable state", and

- complying to the Bangor's SUS adjective scale in Fig. 3 , the framework could be stated as "excellence usability" for each public sector agency of Malaysia. This means the framework could be adopted in assisting each public sector agency of Malaysia to manage the social content.

Besides that, for the overall exercise, based on the calculation of SUS score value in Table IV, the overall mean value of SUS score is "87.73". Therefore, based on the Bangor's SUS adjective scale based on quartiles (Refer Fig. 3 ), the result for overall exercise shows,

- the quartile range for the assessment falls under the " $4^{\text {th }}$ quartile range",

- the acceptability ranges of the proposed framework are at the "acceptable state", and

- complying to the Bangor's SUS adjective scale in Fig. 3 , the framework could be stated as "excellence usability". 
Based on the finding of the means value of SUS score on each public sector agency of Malaysia and the overall exercise, it could be concluded that the proposed social content management framework based on service science perspective is acceptable to be applied in the organisations. It is also showing that the framework is able to guide the organisations to manage their social content.

\section{CONCLUSION}

This article provides an overview of the evaluation of the social content management framework based on service science perspective on the working environment through the implementation of the case study. Agencies under the government of Malaysia are selected as case study because the current direction of the government is to consider the needs of the citizen directly in formulating service innovations offered by the organisation. The SUS score is adapted to show the acceptability state and the usability of the proposed frameworks in real working environment. From the findings, the proposed social content management framework based on service science perspective is acceptable to be applied in the organisations. For future work, the framework needs to be mapped with the actual execution of social content management processes in the respective organisations in order to identify room for improvements for individual organisations and also to perform cross-case analysis to find the similarities and differences between cases.

\section{ACKNOWLEDGMENT}

The study is supported by Research Grant FRGS/2/2014/ICT01/UKM/02/1, Ministry of Education Malaysia, Universiti Kebangsaan Malaysia and Public Service Department of Malaysia.

\section{REFERENCES}

[1] Salman, M. A. M. Salleh, M. A. Yusoff, and M. Y. H. Abdullah, "Political Engagement on Social Media as Antecedent for Political Support among Voters in Malaysia," J. Komunikasi, Malaysian J., vol. 34, no. 2, pp. 152-165, 2018.

[2] M. A. Mohd Sani, S. Hassan, M. K. Ahmad, and Kartini Aboo Talib Khalid, "Generation Y' S Political Participation and Social Media in Malaysia," Malaysian J. Commun., vol. 32 , no. 1, pp. 125-143, 2016.

[3] E. Loukis, Y. Charalabidis, and A. Androutsopoulou, "Promoting open innovation in the public sector through social media monitoring," Gov. Inf. Q., vol. 34, no. 1, pp. 99-109, 2017.

[4] S. Nambisan, K. Lyytinen, A. Majchrzak, and M. Song, "Digital Innovation Management: Reinventing Innovation Management Research in a Digital World,” MIS Q., vol. 41, no. 1, pp. 223-238, 2017.

[5] F. Hilverda, M. Kuttschreuter, and E. Giebels, "Social media mediated interaction with peers, experts and anonymous authors: Conversation partner and message framing effects on risk perception and sensemaking of organic food," Food Qual. Prefer., vol. 56, pp. 107-118, May 2017.

[6] S. L. Vargo and R. F. Lusch, "Institutions and axioms : an extension and update of service-dominant logic," J. Acad. Mark. Sci., vol. 44, pp. 523, 2016.

[7] C. K. Prahalad and V. Ramaswamy, "Co-creating unique value with customers," Strateg. Leadersh., vol. 32, no. 3, pp. 4-9, 2004.

[8] C. K. Prahalad and V. Ramaswamy, "The future of competition: cocreating unique value with customers," Penguin Books India, 2004.

[9] M. Mukhtar, M. N. Ismail, and Y. Yahya, "A hierarchical classification of co-creation models and techniques to aid in product or service design,” Comput. Ind., vol. 63, no. 4, pp. 289-297, 2012.

[10] V. Ramaswamy and K. Ozcan, The co-creation paradigm. Stanford University Press, 2014.

[11] B. Leavy, "Venkat Ramaswamy - a ten-year perspective on how the value co-creation revolution is transforming competition," Strateg. Leadersh., vol. 41, no. 6, pp. 11-17, 2013.

[12] H. Mohamed, N. F. Elias, M. Mukhtar, Y. Yahya, S. A. Hanawi, R. Jenal, and W. A. Z. W. Ahmad, "Model Nilai Cipta-Sama dalam Sistem Pengukuran Prestasi,” J. Pengur., vol. 45, no. 2015, pp. 155-163, June, 2015.

[13] W. A. Z. W. Ahmad, M. Mukhtar, and Y. Yahya, "Developing the Dimensions of a Social Content Management Framework," Int. J. Adv. Sci. Eng. Inf. Technol., vol. 8, no. 2018, October 2018.

[14] W. A. Z. W. Ahmad, M. Mukhtar, and Y. Yahya, "Managing Social Content: A Delphi Study," J. Pengur., vol. 53, no. 2018, pp. 1-20, October 2018.

[15] J. Brooke, "SUS - A quick and dirty usability scale," Usability Eval. Ind., vol. 189, no. 194, pp. 4-7, 1996.

[16] S. C. Peres, T. Pham, and R. Phillips, "Validation of the system usability scale (sus): Sus in the wild," in Proceedings of the Human Factors and Ergonomics Society, pp. 192-196, 2013.

[17] S. Borsci, S. Federici, and M. Lauriola, "On the dimensionality of the System Usability Scale: A test of alternative measurement models," Cogn. Process., vol. 10, no. 3, pp. 193-197, 2009.

[18] N. A. A. Bakar, "Enterprise architecture implementation assessment model for malaysian public sector," Universiti Teknologi Malaysia, 2017.

[19] R. K. Yin, Case Study Research Design and Methods, Fifth. SAGE Publications, Inc, 2014.

[20] EPU, "Rancangan Malaysia Ke-Sebelas 2016-2020,” 2016.

[21] MAMPU, "Pelan Strategik ICT Sektor Awam Malaysia 2016-2020, 2016.

[22] SKMM, “Internet Users Survey 2016," 2016.

[23] SKMM, "Pengurusan Media Sosial Dalam Sektor Kerajaan,” 2016. 